\title{
Filosofia e Geografia: entrelaces em uma perspectiva autobiográfica e literária
}

\author{
Fhilosophy and Geography: interweaving in an autobiographical and \\ literary perspective
}

\author{
Daniel Cardoso Alves \\ Doutorando na Universidade Federal de Minas Gerais, Belo Horizonte, MG, Brasil. \\ dca.uemg@gmail.com - http://orcid.org/0000-0002-1597-5180
}

Recebido em 03 de abril de 2021

Aprovado em 06 de setembro de 2021

Publicado em 08 de novembro de 2021

RESUMO: Este artigo pretende evidenciar as conexões entre autobiografia e experiências no campo da Filosofia por um professor de Geografia. O propósito é explorar o território do conhecimento geográfico destacando as suas zonas de contato com o conhecimento filosófico. Para tanto, adota como argumento a literatura infanto-juvenil de $O$ Pequeno Príncipe que, por suas peculiaridades literárias, filosóficas e geográficas, apresenta-se como evidencia literária para uma tentativa de se estabelecer intersecções entre esses dois campos do saber. Conclui-se enfatizando que a dicotomia de saberes, apesar de ainda ser um paradigma que acompanha a história moderno-positivista da produção do conhecimento, é negada quando limites teóricos e práticos desestabilizam visões reducionistas sobre a formação e atuação profissional docente.

Palavras-chave: Autobiografia; Filosofia; Geografia; Literatura; Professor.

ABSTRACT: This article intends to highlight the connections between autobiography and experiences in the field of Philosophy by a Geography professor. The purpose is to explore the territory of geographic knowledge highlighting its contact zones with philosophical knowledge. Therefore, it adopts as an argument the children's literature of $O$ Pequeno Príncipe which, due to its literary, philosophical and geographical peculiarities, presents itself as literary evidence for an attempt to establish intersections between these two fields of knowledge. It concludes by emphasizing that the knowledge dichotomy, despite still being a paradigm that accompanies the modern-positivist history of knowledge production, is denied when theoretical and practical limits destabilize reductionist views on teacher education and professional performance.

Keywords: Autobiography; Philosophy; Geography; Literature; Teacher. 


\section{Introdução}

A pretensão deste artigo é contribuir para romper com paradigmas reducionistas que, ancorados num positivismo ${ }^{1}$ dogmático, estabelecem distanciamentos entre práticas docentes seccionadas em campos de saber que têm histórias que se intercruzam. No caso específico, trata de reflexões sobre a prática docente em Filosofia da Educação de um licenciado em Geografia. Para tornar evidente as zonas de contato entre Filosofia e Geografia, vale-se da obra literária infanto-juvenil O Pequeno Príncipe ${ }^{2}$.

O seu interesse surge em função de tensões autobiográficas vivenciadas no campo de atuação filosófica tendo formação inicial em Geografia, cujas narrativas de seus pares, pautadas no distanciamento das intersecções, misturas e articulações entre o saber filosófico e o saber geográfico, revelavam-se incompreensíveis para o geógrafo, justamente, por negarem a origem intercruzada Filosofia-Geografia, o que para ele era nítido.

As motivações que levaram à abordagem dessa temática, são atravessadas por várias hipóteses ou suposições narrativas e impressões pessoais do sujeito-autor. Uma delas diz respeito a discursos internos na área de Filosofia e Educação ${ }^{3}$, sugeridos por um ou outro colega que, justificados na formação inicial em Filosofia, defendiam a prioridade dos filósofos da área na escolha dos encargos didáticos, secundarizando o querer do único geógrafo que também integrava a área de Filosofia da Educação e que, de fato e de direito, a ela vinculava-se, já que admitido sob as mesmas regras editalícias dos demais.

Outra motivação refere-se ao fato de que, coincidentemente ou não, o único docente que não pertencia, por não se sentir acolhido, ao núcleo de pesquisas em Filosofia da instituição universitária era este sujeito-autor, um Geógrafo ${ }^{4}$ atuante na Filosofia da Educação.

Como terceira suposição que motivou este artigo, deve-se ao fato de que, não raras vezes, era mencionado, no âmbito interno da área de Filosofia da Educação, e por um ou outro colega, a necessidade de parcerias para produções acadêmicas com filósofos que trabalhavam com a disciplina, cujo enfoque estava sob o ministério do geógrafo professor de Filosofia, deixando a entender, por apreensão pessoal, uma certa inaptidão do mesmo. 
Por fim, também motivou a produção deste texto, os frequentes relatos que chegavam ao geógrafo sobre supostas sondagens nos períodos subsequentes, por parte de alguns colegas de área junto ao corpo discente, acerca dos conteúdos trabalhados por aquele, num tom fiscalizador do trabalho alheio.

Tudo isso causava no docente um sentimento de exclusão e desmerecimento do seu saber, o que ensejou a discussão nesse artigo, constituindo-se, assim, como fruto das nuances autobiográficas acerca da trajetória de participação de um geógrafo no espaço da Filosofia na educação superior, tendo como característica metodológica a singularidade científica da aproximação do autor com o objeto de problematização, dada a oportunidade de ter ele, sujeito-pesquisador, habitado o espaço de problematização e o observado sob o prisma afetivo-aproximado, entretanto, pautando-se na reflexividade científico-metodológica das suas vivências.

Esse vínculo e a trajetória autobiográfica do sujeito-pesquisador - formativa e profissional - é orientado pela perspectiva analítica com base em Delory-Momberguer (2009), o que contribui para o rigor metodológico intentado em "biografar" a sua própria experiência docente.

Por essa base teórico-metodológica, esse artigo é escrito a partir do "saber da experiência" (ALLIAUD; SUÁREZ, 2011; CONTRERAS; PÉREZ DE LARA, 2010) resultante das vivências em um território difuso, mas delimitado pela intersecção entre autobiografia, prática e formação docente.

Todavia, é importante esclarecer que esse estudo, inspirando-se em Suárez (2014)

não é o produto de uma investigação sistemática e exaustiva, na forma de um estado da arte, nem mesmo é o resultado de uma consulta relativamente rigorosa da informação disponível na web. Pelo contrário, este texto é o resultado da minha própria experiência ou, melhor, é o produto da reconstrução da minha própria trajetória em conjunto com outras e, embora não seja propriamente uma autobiografia, tem todas as lacunas, incoerências e desaparecimentos, pontos típicos das "histórias vivas" (Minguzzi, 2011) (SUÁREZ, 2014, p. 765, tradução deste autor).

Nesse sentido, esse texto constitui-se como um quadro carregado das imprecisões que decorrem das memórias e vivências, dos encontros e das conversas com o outro e das 
reminiscências de conhecimentos e experiências anteriores elaboradas pelo sujeito-autor. É, também, com base em Suárez (2014),

\begin{abstract}
um mapa irregular, necessariamente incompleto, que se faz percorrendo o território e seguindo sinais, rastros, intuições, amores à primeira vista, rastros e promessas, bisbilhotando e ativando a própria memória, a dos outros, a já documentada, atualizando outros mapas. Esta cartografia tem a ver com um percurso partilhado e com um percurso singular, e com o olhar particular que se forma no duplo jogo de ter vivido e percorrido aquele espaço e esse tempo e de imediato, tentar objetivar, documentar, aprender essas vivências e experiências, mas tentando alcançar um distanciamento e estranhamento dessa experiência e desse trânsito para traduzi-la em um texto reflexivo (SUÁREZ, 2014, p. 765, tradução deste autor).
\end{abstract}

Trazer à baila essa temática, além de romper com paradigmas que seccionam saberes, valoriza a pesquisa narrativa vinculada ao espaço investigativo autobiográfico que, na Educação, revela-se como um campo fértil em que racionalidades epistemológicas e/ou praxiológicas, ainda são um desafio para o alcance da racionalidade crítica na formação do professor. A autobiografia desestabiliza uma formação que supervaloriza a racionalidade técnica, e insere a racionalidade prática como alternativa, e necessária, para a potencialidade dessa formação com vistas à conquista de uma racionalidade formativa cada vez mais crítica, como ensina Diniz-Pereira (2014).

A discussão aqui proposta tem como finalidade última demarcar a indissociabilidade entre Filosofia e Geografia, não só porque o historiador, geógrafo e filósofo grego Estrabão (1991), em seu célere Tratado, definiu Geografia como uma atividade filosófica, uma vez que os seus primeiros expoentes eram filósofos, dentre os quais, Homero (928- 898 a.C.), Anaximandro (610-546 a.C.), Hecateu (550-476 a.C.), Eratóstenes (276-194 a.C.), Demócrito 460-370 a.C.), Eudoxo (408-355 a.C.), Dicearco (355-285 a.C.), Éforo (405-330 a.C.), Eratóstenes (276-194 a.C.), Políbio (203-120 a.C.), Posidônio (135-51 a.C.), Ptolomeu (100-168 d.C.) e alguns outros; não apenas pelo fato de filósofos modernos como Francis Bacon (1561-1626), David Hume (1711-1776) e Carolus Linnaeus (1707-1778) terem contribuído para que Kant (1724-1804) desenvolvesse suas ideias sobre Geografia, definindo-a como "[...] a primeira parte do conhecimento do mundo [...] isto é o conhecimento que será útil em todas as possíveis circunstâncias da vida" (KANT, 1999, p. 256), o que influenciou, posteriormente, a sistematização epistemológica da Geografia por 
Alexander Von Humboldt (1769-1859) e Carl Ritter (1779-1859), Friedrich Ratzel (1844-1904) e Vidal de La Blache (1845-1918); como também, por ser a Geografia um estado filosófico de pensar o perceptível e o imperceptível do espaço geográfico, cujas materialidades imbricamse com todas as dimensões da vida social.

Portanto, como Deleuze e Guattari (1992), comunga-se, nesse artigo, do entendimento de se pensar Geografia sob a ótica da Filosofia, pelo que, defende-se o emprego do termo Geofilosofia, afastando quaisquer tentativas de cunho dogmático e/ou preconceituoso de se separar conhecimentos que são, na essência, indissociáveis. Nas palavras dos geofilósofos:

[...] a geografia não se contenta em fornecer uma matéria e lugares variáveis para a forma histórica. Ela não é somente humana e física, mas mental, como a paisagem. Ela arranca a história do culto da necessidade, para fazer valer a irredutibilidade da contingência. Ela a arranca do culto das origens, para afirmar a potência de um 'meio' o que a filosofia encontra entre os gregos, dizia Nietzsche, não é uma origem, mas um meio, um ambiente, uma atmosfera ambiente: o filósofo deixa de ser cometa [...] Ela a arranca das estruturas, para traçar as linhas de fuga que passam pelo mundo grego, através do Mediterrâneo. Enfim, ela arranca a história de si mesma para descobrir os devires, que não são a história mesmo quando nela recaem [...] (DELEUZE; GUATTARI, 1992, p. 125).

Em termos estruturais, o artigo se organiza em mais duas seções além dessa introdução, a saber:

Na seção seguinte, denominada de "O Pequeno Príncipe: a metáfora de um geofilósofo?", a tentativa em demonstrar que do todo geógrafo tem um $\mathrm{F}$ de filósofo, assim como todo filósofo tem um $\mathrm{F}$ de geógrafo, é poeticamente comprovada por um jeito literário existencialista de pensar os perceptíveis e imperceptíveis geográficos através de um enredo literário lúdico, existencialista e geográfico.

Com as considerações finais, encerra-se o artigo, resgatando as memórias das vivências profissionais do sujeito-autor, com a intenção de concluir que, na prática e na teoria, Filosofia e Geografia são inseparáveis na busca incansável de se investigar, ou como dizia Foucault (1984), de sacudir as evidências, estranhar-se com as familiaridades dos fenômenos geográficos humanos ou físicos, assim como faz $O$ Pequeno Príncipe em suas viagens questionadoras pelo espaço, pois, "de que valeria a obstinação do saber se ele assegurasse apenas a aquisição dos conhecimentos e não, de certa maneira, o descaminho daquele que conhece?" (FOUCAULT, 1984, p. 13). 


\section{O Pequeno Príncipe: a metáfora de um geofilósofo?}

A escolha por analisar a clássica obra literária O Pequeno Príncipe escrita há quase oito décadas pelo autor francês Antoine de Saint-Exupéry, centrando-se nas cinco virtudes literárias propostas por Calvino (1990), justifica-se, inicialmente, no lugar que ela ocupa na memória ${ }^{5}$ pessoal infanto-juvenil desse examinador, pois, carregada de conteúdo geográfico e filosófico, essa obra esteve presente no seu percurso formativo escolar.

No entanto, o contexto escolarizado em que ocorreu a sua apropriação, resultou na tergiversação da principal finalidade de um texto literário, que é humanizar pelo entretenimento, haja vista que, conforme Cândido (1999, p. 83), "a fantasia quase nunca é pura. Ela se refere constantemente a alguma realidade: fenômeno natural, paisagem, sentimento, fato, desejo de explicação, costumes, problemas humanos [...]". Essa relação entre fantasia e realidade é o que caracteriza a função da literatura dimensionada pelo social e cultural, cuja finalidade última é representar "[...] uma dada realidade social e humana, que faculta maior inteligibilidade com relação a esta realidade" (CÂNDIDO, 1999, p. 86).

Outro motivo que justifica a escolha de O Pequeno Príncipe está no fato de que, em sua releitura, é evidente para esse examinador o encontro entre Filosofia e Geografia no enredo abrangido pela obra. $E$ isso se deve porque, enquanto uma obra clássica, pertence ao grupo daqueles livros que reúnem os quatorze motivos definidos por Calvino (1993) como justificadores da sua leitura e, sempre necessária, releitura.

No caso particular desse examinador, que relê a obra em análise, destacam-se dois motivos principais: "toda releitura de um clássico é uma leitura de descoberta como a primeira" (CALVINO, 1993, p. 11), pelo que, "um clássico é um livro que nunca terminou de dizer aquilo que tinha para dizer" (CALVINO, 1993, p. 11). Ou seja, como geógrafo e professor de Filosofia da Educação, a nova leitura de O Pequeno Príncipe diz mais, passa a desvelar uma Filosofia misturada com uma Geografia humanista do espaço antes não enxergada.

Ambos os motivos instigam esse examinador a reler $O$ Pequeno Príncipe com a expectativa semelhante à de uma primeira leitura e, também, de descobrir mais, visto que, na sua concepção, inspirando-se em Calvino (1993), é uma obra que ainda tem muito a desvelar, sobretudo porque 
[...] o rendimento máximo da leitura dos clássicos advém para aquele que sabe alterná-la com a leitura de atualidades numa sábia dosagem. $E$ isso não presume necessariamente uma equilibrada calma interior: pode ser também o fruto de um nervosismo impaciente, de uma insatisfação trepidante (CALVINO, 1993, p. 14-15).

A busca da medida certa da contextualização ${ }^{6}$ de uma obra clássica, é o que the confere um dinamismo constante. Dessa forma, reler $O$ Pequeno Príncipe traz à baila sensações e/ou preocupações imperceptíveis para esse examinador em contextos espaço-temporais anteriores, especialmente por se tratar, agora, de um momento de leitura realizada por um sujeito adulto, formado em Geografia e profissional da área de Filosofia da Educação que, enquanto pessoa grande e formada, aos olhos do Pequeno Príncipe, lúcida, esquisita, bizarra, materialista, racional, envelhecida, aspirante em conhecer a natureza literária e os valores verbais e imagéticos que a obra se apropria para fazer cumprir a sua finalidade, muito provavelmente, voltará sua atenção "[...] à geografia, à história, ao cálculo, à gramática [...]" (SAINT-EXUPÉRY, 2015, p. 4), pois, agora, comporta-se como

\begin{abstract}
as pessoas grandes (que) adoram os números. Quando a gente lhes fala de um novo amigo, elas jamais se informam do essencial. Não perguntam nunca: "Qual é o som da sua voz? Quais os brinquedos que prefere? Será que ele coleciona borboletas? "Mas perguntam: "Qual é sua idade? Quantos irmãos tem ele? Quanto pesa? Quanto ganha seu pai?" Somente então é que elas julgam conhecê-lo. Se dizemos às pessoas grandes: "Vi uma bela casa de tijolos cor-derosa, gerânios na janela, pombas no telhado. . . " elas não conseguem, de modo nenhum, fazer uma idéia da casa. É preciso dizer-lhes: "Vi uma casa de seiscentos contos". Então elas exclamam: "Que beleza!" Assim, se a gente lhes disser: "A prova de que o principezinho existia é que ele era encantador, que ele ria, e que ele queria um carneiro. Quando alguém quer um carneiro, é porque existe" elas darão de ombros e nos chamarão de criança! Mas se dissermos: "O planeta de onde ele vinha é o asteróide B 612" ficarão inteiramente convencidas, e não amolarão com perguntas. Elas são assim mesmo. É preciso não thes querer mal por isso. As crianças devem ser muito indulgentes com as pessoas grandes (SAINT-EXUPÉRY, 2015, p. 47).
\end{abstract}

Por isso, se apenas naturalista do espaço, pouco importariam os sentidos poéticos das imagens, as perguntas existenciais e a capacidade imaginativa de se auto representar na narrativa que arrisca a ler pela terceira vez, já que, nessa fase da vida, a do ser adulto, é comum a realização de leituras levianas, que podam as asas da imaginação. Porém, como um geógrafo na Filosofia, continuará ao sadio devaneio 
literário de pensar sobre si e o espaço num percurso não linear entre fantasia e realidade.

A despeito, atitude adulta é um dos grandes temores de Saint-Exupéry (2015) que, introdutoriamente à página 13, explicita o fato de não ter iniciado a história "à moda dos contos de fada" se auto corrigindo ao dedicar o livro às pessoas pequenas que moram nas pessoas grandes, ainda que aquelas sejam esquecidas por estas.

Mas, retomando à ideia de Calvino (1993), para o qual a leitura e releitura de um clássico é sempre incompleta e, pensando como Saint-Exupéry (2015) na possibilidade das pessoas grandes, a exemplo desse examinador, em sua constituição identitária geofilosófica, resgatarem, pela literatura, as pessoas pequenas que nelas moram, é que se analisou e interpretou a clássica obra O Pequeno Príncipe à luz das cinco virtudes literárias propostas por Calvino (1990), para se captar a dimensão geofilosófica materializada na função social da literatura que, conforme Cândido (1999), ao mesmo tempo que humaniza, também aliena, pois fantasia e realidade se misturam, se conciliam em devaneio, termo esse que, para o filósofo Gaston Bachelard, segundo explica Cândido (1999), deixou de se referir exclusivamente a

[...] um estado de passividade intelectual a ser anulado. Mas aos poucos o devaneio Ihe foi aparecendo, não apenas como etapa inevitável, ou solo comum a partir do qual se bifurcam reflexão científica e criação poética, mas a condição primária de uma atividade espiritual legítima. $O$ devaneio seria o caminho da verdadeira imaginação, que não se alimenta dos resíduos da percepção e, portanto, não é uma espécie de resto da realidade; mas estabelece séries autônomas coerentes, a partir dos estímulos da realidade. Uma imaginação criadora para além, e não uma imaginação reprodutiva ao lado, para falar como ele. $O$ devaneio (rêverie) se incorpora à imaginação poética e acaba na criação de semelhantes imagens; mas o seu ponto de partida é a realidade sensível do mundo, ao qual se liga assim necessariamente (CÂNDIDO, 1999, p. 83).

Diante dessas premissas, entende-se que O Pequeno Príncipe, de um modo geral, mescla fantasia com humanização ao trazer à baila questões existenciais com a leveza característica de um texto literário, em que o narrador, ao assumir a condição da personagem - um piloto cujo avião sofre uma pane -, se vê confinado num deserto, onde inicia um diálogo com uma criança risonha - O Pequeno Príncipe - de cabelos de ouro e questionadora das coisas da vida, insignificantes aos olhos dos adultos. 
Esse diálogo, um convite implícito ao leitor que se traduz em uma forte relação com o personagem narrado, é interpretado por Bernardo (2005) como catarse, processo em que

\begin{abstract}
o leitor assume no decorrer da leitura, sem o perceber com clareza, uma nova identidade, o que torna inestimável a experiência estética. A catarse, então, é menos um processo de identificação sumária do leitor, que finge o personagem ou vive o que ele gostaria de dizer ou viver, do que um processo de reidentificação. O leitor torna-se, sem o perceber com clareza, um outro. A leitura do mundo através da perspectiva diferente do personagem modifica, por sua vez, a perspectiva do leitor, o que implica uma alteração substancial na sua própria identidade. Ou seja, a catarse não implica uma identificação que acalme porque, afinal, se tem uma identidade e se sabe que se é, mas sim uma mudança de identidade, que pode ser dolorosa, mas é sempre enriquecedora (BERNARDO, 2005, p. 21).
\end{abstract}

O diálogo identitário adota como pano de fundo uma viagem planetária conduzida pelo olhar da criança, que percebe o mundo gigante à sua volta. Nessa viagem, as duas personagens centrais (a criança e o piloto) - e que à luz do clássico filósofo Aristóteles (1986) poderiam ser entendidas mitologicamente como uma única personagem em conflito interno de consciência, lutando contra sentimentos que Ihe tiram a natureza ideal de ser humano, isto é, ambas personificadas na abstração do Pequeno Príncipe como o próprio Eu-leitor -, travam reflexões que provocam no leitor a ressiginificação dos seus valores humanos em direção à busca do sentido da vida, que é alcançado, de forma dramática, ao final da história com um desfecho poético, o que, no campo da Filosofia Grega, poderia ser denominado parresia, uma virtude socrático-filosófica que se traduz na coragem da verdade de se mergulhar nos próprios dramas.

O desfecho poético-literário verificado em O Pequeno Príncipe é comum em obras tradicionais, haja vista o estilo linguístico e narrativo - encadeamento de situações fantasiosas com a intensão de abordar um tema denso de cunho existencialista, a angústia suicida, empregados pelo autor.

Ainda que não tenha iniciado o livro com a célere frase dos contos de fadas "Era uma vez ...", como explicita no início da história, Saint-Exupéry (2015) acaba estruturando a obra com idêntico estilo lúdico tradicional: descrição e surgimento mágico da personagem $O$ Pequeno Príncipe, problemática em torno dos baobás, desencadeamento narrativo de acontecimentos no decorrer da viagem planetária na 
perspectiva de um final encantado com o conserto do avião e suicídio metafórico ${ }^{7}$ do Pequeno Príncipe, que retorna a ser uma estrela dourada e docilmente sorridente, gerando no leitor a expectativa de continuidade da história.

Em uma análise mitológica, a obra, por mais que seja um clássico com narrativa que caminha do fantástico ao real-existencial, portanto, caracterizada por uma abordagem metafísica, não se constitui estritamente no campo da mitologia, mas como uma literatura infanto-juvenil com demasiada carga das questões humanas, o que instiga a emergência de um pensamento filosófico-mitológico, já que, o enredo é, em si, o processo de criação de uma nova consciência existencial no leitor, o qual é, constantemente, convidado a um esforço interpretativo da trama, que lhe aguça novos patamares de consciência.

A esse respeito destaca-se que mito, à luz do mitólogo Eliade (1972), "conta uma história sagrada; ele relata um acontecimento ocorrido no tempo primordial, o tempo fabuloso do "princípio". É sempre, portanto, a narrativa de uma "criação": ele relata de que modo algo foi produzido e começou a ser" (ELIADE, 1972, p.11). No quesito da criação do nascimento de uma nova consciência, insere-se O Pequeno Príncipe, porém, distancia-se da ideia do mito por não trazer em si a ideia do sagrado, por exemplo.

Assim, esses novos patamares de consciência, em O Pequeno Príncipe, estão imbricados com uma trama carregada de pensamento existencialista ${ }^{8}$ sobre a vida, o ser e as coisas do mundo, metamorfoseado no espaço planetário.

Por existencialismo, corrente típica da Filosofia predominante no século $\mathrm{XX}$, entende-se como uma consciência filosófica que

[...] tendeu a dar maior importância ao finito, isto é, ao que surge e desaparece, ao que tem fronteiras e limites. Esse interesse pelo finito aparece, por exemplo, numa corrente filosófica (entre os anos 30 e 50) chamada existencialismo e que definiu o humano ou o homem como "um ser para a morte", isto é, um ser que sabe que termina e que precisa encontrar em si mesmo o sentido de sua existência (CHAUI, 2001, p. 64).

Dada essa carga existencialista, O Pequeno Príncipe revela-se como uma narrativa densa, cuja vestimenta literária construída pelas virtudes linguísticas leveza, rapidez, exatidão, visibilidade e multiplicidade, definidas por Calvino (1990), dão-lhe uma característica poética e cumpre, ao mesmo tempo, a finalidade social do texto literário que, 
como já exposto, é "confirmar a humanidade do homem" (CÂNDIDO, 1999, p. 81) pelo entretenimento.

Com leveza, Saint-Exupéry (2015) provoca o encantamento cognitivo no leitor, ou seja, a racionalização precisa do seu pensamento por outrem a partir da utilização de artifícios poéticos de linguagem, como se extrai dos excertos:

tive, pois, de escolher uma outra profissão e aprendi a pilotar aviões. Voei, por assim dizer, por todo o mundo (SAINT-EXUPÉRY, 2015, p. 4).

Mergulhou então num pensamento que durou muito tempo. Depois, tirando do bolso o meu carneiro, ficou contemplando o seu tesouro (SAINT-EXUPÉRY, 2015, p. 9).

Conforme Calvino (1990, p. 22), "a leveza é algo que se cria no processo de escrever, com os meios linguísticos próprios do poeta". Nos excertos acima, verifica-se esse estilo particular do autor em dizer a mensagem de uma forma metafórica, suave em relação ao exercício do pensamento humano.

Com o estilo literário da rapidez, Saint-Exupéry (2015) estimula a produção de sentido ao texto pelo leitor. Esse, diante de discursos silentes, divagantes ou organizados de forma a provocar sensações de agilidade, mobilidade e desenvoltura, é provocado a complementar os sentidos pensados pelo autor, como se depreende:

\footnotetext{
- Bom dia, disse o principezinho. Você tem um chapéu engraçado. - É para agradecer, exclamou o vaidoso. Para agradecer quando me aclamam. Infelizmente não passa ninguém por aqui. - Sim? disse o principezinho sem compreender. - Bate as mãos uma na outra, aconselhou o vaidoso. $\mathrm{O}$ principezinho bateu as mãos uma na outra. $O$ vaidoso agradeceu modestamente, erguendo o chapéu (SAINT-EXUPÉRY, 2015, p. 34).

Pus-me de pé, como atingido por um raio. Esfreguei os olhos. Olhei bem. E vi um pedacinho de gente inteiramente extraordinário, que me considerava com gravidade. Eis o melhor retrato que, mais tarde, consegui fazer dele (SAINTEXUPÉRY, 2015, p. 5).
}

Nessa mesma direção, Belmiro (2014, p. 6) explica que "as lacunas que os textos literários contêm convidam o leitor a recorrer aos seus conhecimentos prévios para darIhes sentido [...] convocando o leitor a se tornar sujeito da produção de sentidos, mais do que fazendo-o acompanhar simplesmente o enredo".

Nos supracitados momentos - quando da aparição do Pequeno Príncipe e quando do diálogo com o personagem Vaidoso - há um desencadeamento sequenciado 
das ações com supressões de informações que provocam o leitor a produzir o sentido, o movimento da narração. Essa provocação da participação do leitor para a produção de sentido é o que Calvino (1990, p. 59) denomina de rapidez de estilo e de pensamento literário, ou seja: "[...] agilidade, mobilidade, desenvoltura; qualidades estas que se combinam com uma escrita propensa às divagações, a saltar de um assunto para outro, a perder o fio do relato para reencontrá-lo, ao fim de inumeráveis circunlóquios".

Saint-Exupéry (2015) faz uso de uma linguagem certa, planejada e objetiva, porém, de forma comedida, a fim de que essa virtude literária, denominada por Calvino (1990, p. 72) de exatidão, "[...] linguagem que seja a mais precisa possível como léxico e em sua capacidade de traduzir as nuanças do pensamento e da imaginação, não anule a leveza característica do texto literário."

Diversas são as passagens em que se verifica a presença estilística dos três tipos de exatidão caracterizados por Calvino (1990): precisão, clareza na imagem e tradução do pensamento. Dentre essas passagens, destaca-se a descrição da finalidade pragmática e objetiva da ciência: "E a geografia, é claro, me serviu muito. Sabia distinguir, num relance, a China e o Arizona. É muito útil, quando se está perdido na noite" (SAINT-EXUPÉRY, 2015, p. 4).

Tem-se aqui uma definição pragmática do conhecimento geográfico, que vai sendo alargada à medida que $O$ Pequeno Príncipe começa a explorar a dimensão humana de cada um dos planetas por ele alcançado. Com isso, a Geografia é retratada na obra como um veículo para a inserção na essência do ser pelo espaço explorado, não se encerrando no utilitarismo, pelo contrário, se consolida na finalidade filosóficogeográfica de mergulhar nas angústias humanas, de interpretar as espacialidades, em último, de fazer geograficidade, palavra que para Moreira (2004) significa a expressão da consciência geográfica sobre a apropriação sociocultural do espaço pelo homem, carregando consigo a ideia

de existencialidade, que se contrapõe ao conceito de contextualidade. Tirado numa analogia do conceito de historicidade utilizada pelos historiadores, que é usualmente mais corrente na literatura geográfica contemporânea, a geograficidade extrapola o sentido puro do contexto, centrando seu conteúdo no sentido da existência ou do contexto (espacial) da existência (MOREIRA, 2004, p. 34). 
Geograficidade é ver o espaço para lê-lo humanamente, pelo que, a Visibilidade é um valor linguístico-literário que envolve "[...] dois tipos de processos imaginativos: o que parte da palavra para chegar à imagem visiva e o que parte da imagem visiva para chegar à expressão verbal” (CALVINO, 1990, p. 99). Refere-se a uma construção lexical de um texto imagético pelo leitor, resultante da relação autor-imagem-leitor-cognição, na perspectiva de que o leitor seja capaz de imaginar o pensamento imagético do autor. Essa virtude é problematizada, sobretudo, na crítica à falta de capacidade imaginativa do adulto, como se destaca:

refleti muito então sobre as aventuras da selva, e fiz, com lápis de cor, o meu primeiro desenho. Meu desenho número 1 era assim: Mostrei minha obra-prima às pessoas grandes e perguntei se o meu desenho lhes fazia medo. Responderam-me: "Por que é que um chapéu faria medo?" Meu desenho não representava um chapéu. Representava uma jibóia digerindo um elefante. Desenhei então o interior da jibóia, a fim de que as pessoas grandes pudessem compreender. Elas têm sempre necessidade de explicações (SAINT-EXUPÉRY, 2015, p. 4).

A mencionada virtude literária é central em toda a obra, visto que a problemática surge com a apreensão de sentido de uma imagem - o desenho de um elefante sendo engolido por uma jiboia, mas que os adultos só enxergavam um chapéu - e se encerra com uma imagem - uma estrela dourada num cenário desértico -, assim caracterizada pelo narrador:

esta é, para mim, a mais bela paisagem do mundo, e também a mais triste. É a mesma da página precedente. Mas desenhei-a de novo para mostrá-la bem. Foi aqui que o principezinho apareceu na terra, e desapareceu depois. Olhem atentamente esta paisagem para que estejam certos de reconhecê-la, se viajarem um dia na África, através do deserto. E se acontecer passarem por ali, eu thes suplico que não tenham pressa e que esperem um pouco bem debaixo da estrela! Se então um menino vem ao encontro de vocês, se ele ri, se tem cabelos de ouro, se não responde quando interrogam, adivinharão quem é. Então, por favor, não me deixem tão triste; escrevam-me depressa que ele voltou... (SAINT-EXUPÉRY, 2015, p. 71).

Ainda acerca da visibilidade, é nítida a interdependência que o autor cria entre texto e imagem, reforçando a característica híbrida da linguagem ou, como ele mesmo descreve, "A linguagem é uma fonte de mal-entendidos" (SAINT-EXUPÉRY, 2015, p. 54), por isso, narra o autor: "é preciso ser paciente, respondeu a raposa. Tu te sentarás 
primeiro um pouco longe de mim, assim, na relva. Eu te olharei com o canto do olho e tu não dirás nada" (SAINT-EXUPÉRY, 2015, p. 54). Ou seja, essa situação demandava um olhar atento por parte do Pequeno Príncipe, o que

[...] significa sair do gesto primário de captar algo com os olhos, que é uma atividade física, e passar para outro estágio, aquele em que, a partir de muitos exercícios mentais, absorvemos e compreendemos o examinado. Esse debruçar-se sobre o que os olhos captam provocará análises e, o mais produtivo, provavelmente ativará a capacidade de inventar. Olhar, portanto, é uma soma que inclui o físico, o psicológico, a percepção e a criação (RAMOS, 2011, p. 34).

Também, conforme Ramos (2011, p. 102), "nada em uma ilustração é gratuito. Isso significa que o leitor curioso poderá correlacionar as ilustrações com uma série de temas e outras expressões artísticas". Essa afirmação da autora é observável, sobretudo, em relação à personagem do sujeito vaidoso, cuja crítica implícita somente é percebida na associação com a imagem de um palhaço. Nesse sentido, a imagem complementa a crítica do texto escrito, tornando-a híbrida, multimodal, já que constituída de três premissas fundantes:

[...] 1. O significado é feito com diferentes recursos semióticos, cada um oferecendo distintas potencialidades e limitações; 2 . A criação de significado envolve a produção de todos multimodais; 3 . Se quisermos estudar o significado, precisamos atender a todos os recursos semióticos sendo usado para fazer um todo completo (BEZEMER; JEWITT, 2018, p. 2).

Uma quinta virtude literária presente na obra é a multiplicidade, um valor linguístico-literário que busca, por trás da finalidade de entretenimento da obra literária, transmitir uma informação não literária, a exemplo de:

as pessoas grandes aconselharam-me deixar de lado os desenhos de jibóias abertas ou fechadas, e dedicar-me de preferência à geografia, à história, ao cálculo, à gramática [...] E a geografia, é claro, me serviu muito. Sabia distinguir, num relance, a China e o Arizona. É muito útil, quando se está perdido na noite (SAINT-EXUPÉRY, 2015, p. 4).

Quando o astrônomo descobre um deles, dá-lhe por nome um número. Chama-o, por exemplo: "asteróide 3251" [...]. Tenho sérias razões para supor que o planeta de onde vinha o príncipe era o asteróide B 612. Esse asteróide só foi visto uma vez ao telescópio, em 1909, por um astrônomo turco (SAINT-EXUPÉRY, 2015, p. 11). 
Nas palavras de Calvino (1990, p. 121), a multiplicidade é uma característica literária que tratará, por exemplo, "o romance contemporâneo como enciclopédia, como método de conhecimento, e principalmente como rede de conexões entre os fatos, entre as pessoas, entre as coisas do mundo". Nos excertos acima, o privilégio do conteúdo informativo em detrimento do conteúdo literário é perceptível e também traduz uma das virtudes do texto literário.

Portanto, valendo-se de todas essas virtudes literárias, Saint-Exupéry (2015), ao descrever sete planetas habitados por personagens únicas e visitados durante a sua viagem geográfica, expõe críticas às formas de governo (o planeta do rei solitário), à vaidade solitária do ser (o planeta do vaidoso), à melancolia e manipulação do ser (o planeta do bêbado), ao utilitarismo das coisas (o planeta do homem de negócios) e do belo (o planeta do acendedor de lampiões), à efemeridade e à guerra (o planeta do geógrafo) e à impossibilidade de se viver num planeta habitado por pessoas que não enxergam a verdade essencial da vida (o planeta Terra).

Em suma, se à luz de Moreira (2004), Saint-Exupéry (2015), através do Pequeno Príncipe, faz geograficidade, pela teoria foucaltiana, o mesmo Pequeno Príncipe pratica a inquietação filosófica, virtude que se dá pelo

reinterrogar as evidências e os postulados, sacudir os hábitos, as maneiras de fazer e de pensar, dissipar as familiaridades aceitas, retomar a medida das regras e das instituições, e ao partir desta reproblematização (onde ele desempenha seu papel específico de intelectual), participar da formação de uma vontade política (onde ele tem seu papel de cidadão a desempenhar) (FOUCAULT, 1984, p. 22).

É fato que, em O Pequeno Príncipe, Saint-Exupéry (2015) literariamente faz Geofilosofia, instigando o leitor ao pensamento crítico sobre o mundo/espaço, desvelando dimensões da vida social, humana e política, a partir da compreensão de si, dos valores que carregam o ser.

A finalidade última de Saint-Exupéry (2015) é tratar das questões existenciais que envolvem a vida, situada num contexto imperialista de pós II Guerra Mundial, pela literatura e, sem dúvida, cumpre a partir de uma poética em tratar questões humanas densas pelo filosofar, assim problematizado por Foucault (1984): 


\begin{abstract}
mas o que é filosofar hoje em dia - quero dizer, a atividade filosófica - senão o trabalho crítico do pensamento sobre o próprio pensamento? Se não consistir em tentar saber de que maneira e até onde seria possível pensar diferentemente em vez de legitimar o que já se sabe? Existe sempre algo de irrisório no discurso filosófico quando ele quer, do exterior, fazer a lei para os outros, dizer-lhes onde está a sua verdade e de que maneira encontrá-la, ou quando pretende demonstrar-se por positividade ingênua; mas é seu direito explorar o que pode ser mudado, no seu próprio pensamento, através do exercício de um saber que lhe é estranho [...] (FOUCAULT, 1984, p. 13).
\end{abstract}

Ante o exposto, obra $O$ Pequeno Príncipe revela-se como uma literatura geofilosófica de difícil enquadramento literário e etário dadas as temáticas abordadas que ultrapassam o mundo da infância, o que desestabiliza um viés analítico determinista e meramente classificatório. Desestabilidade que se adequa ao exercício do pensamento filosófico e à construção do raciocínio geográfico que não aceitam encaixotamentos deterministas.

Por fim, negativamente, revela-se como um braço, naquele tempo, para ratificar o imaginário e o ideário eurocêntricos dominantes, tanto do ponto de vista político, quanto epistêmico $^{9}$, o que demanda uma abordagem futura e mais aprofundada sobre esse aspecto, quem sabe à luz de uma análise geofilosófica crítica.

\title{
Considerações finais
}

Conclui-se, pelas correlações literárias estabelecidas entre Filosofia e Geografia Humanistas, que ambas se mesclam na compreensão do lugar do ser no planeta, pelo que, afirmar que todo Geógrafo é antes um filósofo humanista do espaço, não trata-se apenas de paralelismo, de uma coincidência do grafema $F$ presente nos dois termos, mas dos sentidos que ambos carregam em relação ao questionamento das familiaridades materializadas no espaço geográfico apropriado por humanos. Compreender os perceptíveis e os imperceptíveis dos fenômenos geográficos nos espaços habitados e imaginados, o que é feito pelo Pequeno Príncipe, é, portanto, um fazer geofilosófico.

A figura do Pequeno Príncipe é uma metáfora que ganha veracidade no conceito interdependente de Filosofia e Geografia, isto é, de Geofilosofia, visto que, não há como se analisar o espaço geográfico desconsiderando o humano que dele se apropria, assim 
como não é possível compreender o humano sem a análise do processo de apropriação do seu espaço.

A própria história evolutiva da Filosofia, dividida entre filósofos pré-socráticos, dedicados às questões naturalistas, e socráticos, pautados nas questões humanistas, ensinou sobre a impossibilidade de encontrar respostas para os questionamentos fundamentais da vida - Quem sou? Para onde vou? De onde vim? Qual é a minha origem? Qual é o meu destino? Eu tenho um papel a cumprir? O que é o homem? O que é mundo? O que é conhecimento? O que é o espaço? - privilegiando apenas uma das dimensões (naturalista ou humana) que elas envolvem.

A Geografia pré-socrática, assim como a Filosofia anterior a Sócrates, avançou para a Geografia e Filosofia socráticas, ou seja, para uma Geofilosofia socrática, já que preocupada com o espaço humanizado. Definitivamente, extrapolou-se, na ciência geográfica, a dicotomia analítica do espaço físico-humana para, então, ser possível apreender os fenômenos do espaço humanamente habitado.

Por todo o exposto nesse texto, teórico e poeticamente, formativo e profissionalmente, científico e filosoficamente, conclui-se que discursos que desconsideram a interdependência entre os conhecimentos filosófico e geográfico, tendendo a um positivismo cego formativo de ensino desses saberes e prático, de atuação em ambos os campos, sob o crivo dos encaixotamentos modernos das áreas do saber, negam a própria história da origem e da finalidade de uma Filosofia pré-socrática (naturalista) para uma metamorfose humanista (socrática), cerrando-se, por fim e cegamente, numa cisão da totalidade do conhecimento geofilosófico indispensável para a compreensão do espaço pelo homem e desse por aquele.

\section{Referências}

ALLIAUD, Andrea; SUÁREZ, Daniel. El saber de la experiencia. Narrativa, investigación y formación docente, col. Narrativas, (auto)biografías y educación, núm. 3, Buenos Aires: Editorial de la Facultad de Filosofía y Letras de la Universidad de Buenos Aires y Consejo Latinoamericano de Ciencias Sociales, 2011.

ARISTÓTELES. Poética. Trad., Prefácio, Introdução, Comentários e Apêndices de Eudoro de Souza. São Paulo: Ed. Abril Cultural, 1986. 
BELMIRO, Celia Abicalil. Provocação e imaginação: diálogos entre narração e descrição na literatura infantil. Idioma, Rio de Janeiro, n² 27, p. 06-18, 2 . Sem. 2014.

BERNARDO, Gustavo. A qualidade da invenção. In: OLIVEIRA, leda de. O que é qualidade em literatura infantil e juvenil? Com a palavra o escritor. São Paulo, DCL: 2005.

BEZEMER, Jeff; JEWITT, Carey. Multimodality: A guide for linguists. Manuscript to appear in L. Lotosseliti (ed.) Research Methods in Linguistics (2nd edition). London: Continuum, 2018. Disponível em: https://core.ac.uk/download/pdf/227335935.pdf. Acesso em: 09 set. 2020.

CALVINO, Ítalo. Seis propostas para o próximo milênio. Trad. Ivo Barroso. São Paulo: Cia. Das Letras, 1990.

CALVINO, Ítalo. Por que ler os clássicos. In: Por que ler os clássicos. São Paulo: Companhia das Letras, 1993.

CANDIDO, Antônio. A Literatura e a Formação do homem. Remates de Males. Antonio Candido. Campinas: Editora UNICAMP, 1999.

CHAUÍ, Marilena. Convite à filosofia. São Paulo: Ática, 2001.

CONTRERAS, José; PÉREZ DE LARA, Nuria. La experiencia y la investigación educativa, en J. Contreras y N. Pérez de Lara (comps.), Investigar la experiencia educativa, Madrid: Morata, 2010, p. 21-88.

DELEUZE, G.; GUATTARI, F. O que é a filosofia? São Paulo: Editora 34, 1992.

DELORY-MOMBERGER, Christine. Biografía y educación. Figuras del

individuoproyecto, col. Narrativas, (auto)biografías y educación, núm. 1, Buenos Aires: Editorial de la Facultad de Filosofía y Letras de la Universidad de Buenos Aires y Consejo Latinoamericano de Ciencias Sociales, 2009.

DINIZ-PEREIRA, J. E. Da racionalidade técnica à racionalidade crítica: formação docente e transformação social. Perspectivas em Diálogo: Revista de Educação e Sociedade, v. 1, p. 21-33, 2014. Disponível em: file:///C:/Users/DELL/Downloads/15Texto\%20do\%20artigo-37-1-10-20140612\%20(1).pdf. Acesso em 25 fev. 2021.

ELIADE, Mircea. Mito e realidade. São Paulo: Perspectiva, 1972.

ESTRABÓN. Geografía. Libros I y II. Introducción general de J. García Blanco; Introducción y notas de J. L. García Ramón y J. García Blanco, Madrid: Editorial Gredos, 1992, p. 559.

FOUCAULT, Michel. Le Souci de la Verite, Magazine Littéraire, n. 207 (mai./1984).

GIDDENS, Anthony. Comte, Popper e o Positivismo. In: GIDDENS, Anthony. Política, Sociologia e Teoria Social. São Paulo: UNESP, 1998. 
HEIDEGGER, M. Que é metafisica? Os Pensadores. Tradução de Ernildo Stein. São Paulo: Abril Cultural, 1989.

KANT, Immanuel. Géographie. Physische Geographie. Paris: Aubier, Tradução de Michèle Cohen-Halimi, Max Marcuzzi et Valérie Seroussi, 1999.

MIGNOLO, Walter D. Desobediência epistêmica: opção descolonial e o significado de identidade em política. Trad. Ângela Lopes Norte. Cadernos de Letras da UFF Dossiê: Literatura, língua e identidade, nº 34, p. 287-324, 2008.

MINGUZZI, Laura. La historia rechazada, historia como vida signifi cante, Revista Duoda (Barcelona), núm. 40, 2011, p. 66-75.

MOREIRA, Ruy. Marxismo e Geografia (A geograficidade e o diálogo das ontologias). GEOgraphia, Rio de Janeiro, n. 11, 2004.

RAMOS, Graça. A Imagem nos livros infantis: caminhos para ler o texto visual. Belo horizonte: Autêntica, 2011.

SAINT-EXUPÉRY, Antoine de. O Pequeno Príncipe. Trad.: André Telles e Rodrigo Lacerda. Saraiva, 2015 [1943]. Disponível em: file://C:/Users/DELL/Downloads/Pequeno\%20Pri\%CC\%81ncipe.pdf. Acesso em: 10 set. 2020.

SUÁREZ, Daniel H. Espacio (auto)biográfico, investigación educativa y formación docente en Argentina: un mapa imperfecto de un territorio en expansión. Revista mexicana de investigación educativa, 2014, v. 19, N. 62, p. 763-786.

\section{Notas:}

1 "No positivismo de Comte, não era possível encontrar um lugar para o sujeito pensante: a psicologia nem mesmo aparecia na hierarquia das ciências e a noção de experiência subjetiva era encarada como uma ficção metafísica" (GIDDENS, 1998, p. 184).

${ }^{2}$ A mencionada obra foi objeto de uma atividade avaliativa requerida pelas profas. Dras. Celia Belmiro e Telma Silva responsáveis pelo ministério, no $1^{\circ}$ semestre de 2020 , da disciplina Processos e discursos educacionais II: Universidade, Leitura Literária e Formação de Leitores do Programa de Pós-Graduação em Educação: Conhecimento e inclusão social da Faculdade de Educação da Universidade Federal de Minas Gerais (PPGE/FaE/UFMG).

${ }^{3}$ Do curso de Licenciatura em Pedagogia de uma universidade pública brasileira.

${ }^{4}$ Posteriormente, instigado por esse contexto de tratamento diferenciado na área, o professor licenciou-se em Filosofia e Pedagogia.

${ }^{5}$ A sua releitura, já na fase final da adolescência, foi uma forte condicionante pela escolha profissional deste examinador que, mirando-se no Pequeno Príncipe, quis tornar-se geógrafo, não para ser um cientista descritor naturalista do espaço, mas um viajante humanista, um geofilósofo do espaço. 
${ }^{6}$ No contexto atual faz-se necessária uma leitura que problematize os traços misóginos (apenas a flor é personagem feminina, porém, retratada como um ser falso e frágil), etnocêntricos, dogmáticos, universalistas e colonizadores demasiadamente reforçados em seu enredo.

${ }^{7}$ Aqui interpretado como parresia.

8 "A palavra existência designa um modo de ser e, sem dúvida, do ser daquele ente que está aberto para a abertura do ser, na qual se situa, enquanto a sustenta" (HEIDEGGER, 1989, p. 59).

${ }^{9}$ É uma obra que precisa ser problematizada à luz de Mignolo (2008), visto que é uma obra que se insere num modus operandi narrativo centrado na supervalorização da figura masculina, na representação de fenótipos humanos europeus fundada em ideais mono-tópicos, ratificando-se um tipo de literatura não interessada com a desobediência epistêmica e política, já que distanciada de sua função transgressora.

\section{(c) (1) (8)(2)}

This work is licensed under a Creative Commons Attribution-NonCommercial 4.0 International (CC BY-NC 4.0) 